\title{
A potent chemotherapeutic strategy in prostate cancer: $S$-(methoxytrityl)-L-cysteine, a novel Eg5 inhibitor
}

\author{
Nai-Dong Xing ${ }^{1,2}$, Sen-Tai Ding ${ }^{1,2}$, Ryoichi Saito ${ }^{1}$, Koji Nishizawa ${ }^{1}$, Takashi Kobayashi ${ }^{1}$, Takahiro Inoue ${ }^{1}$, \\ Shinya Oishi ${ }^{3}$, Nobutaka Fujii ${ }^{3}$, Jia-Jv Lv ${ }^{2}$, Osamu Ogawa ${ }^{1}$ and Hiroyuki Nishiyama ${ }^{1}$
}

Docetaxel-based combination chemotherapy remains the predominant treatment for castration-resistant prostate cancer. However, taxane-related drug resistance and neurotoxicity have prompted us to develop substitute treatment strategies. Eg5 (kinesin spindle protein), which is crucial for bipolar spindle formation and duplicated chromosome separation during the early phase of mitosis, has emerged as an attractive target for cancer chemotherapy. The aim of this study was to investigate the anticancer efficacy of $S$-(methoxytrityl)-L-cysteine (S(Me0)TLC), a novel Eg5 inhibitor in prostate cancer. Eg5 expression was examined in human prostate cancer cell lines and tissue microarrays were constructed from clinical specimens. Antiproliferative activity of $\mathrm{S}(\mathrm{MeO}) \mathrm{TLC}$ in prostate cancer cells was assessed by a cell viability assay. The anticancer effect and inhibitory mechanism of S(MeO)TLC in prostate cancer cells was further explored by Hoechst staining, flow cytometry and immunofluorescence. In addition, the antitumor effect of $\mathrm{S}(\mathrm{MeO})$ TLC on subcutaneous xenograft models was assessed. Eg5 expression was identified in PC3, DU145 and LNCaP cells. More than half of prostate cancer clinical specimens displayed Eg5 expression. $\mathrm{S}(\mathrm{MeO}) \mathrm{TLC}$ exhibited more powerful anticancer activity in prostate cancer cells compared with the other four Eg5 inhibitors tested. S(MeO)TLC induced cell death after arresting dividing cells at mitosis with distinct monopolar spindle formation. $\mathbf{S}(\mathrm{MeO})$ TLC exhibited its significant inhibitory activity $(\boldsymbol{P}<0.05)$ on subcutaneous xenograft models also through induction of mitotic arrest. We conclude that Eg5 is a good target for prostate cancer chemotherapy, and $\mathrm{S}(\mathrm{MeO}) \mathrm{TLC}$ is a potent promising anticancer agent in prostate cancer.

Asian Journal of Andrology (2011) 13, 236-241; doi:10.1038/aja.2010.171; published online 7 February 2011

Keywords: Eg5 protein; prostate cancer; S-(methoxytrityl)-L-cysteine

\section{INTRODUCTION}

Prostate cancer is one of the most commonly diagnosed malignancies and the second highest cause of cancer death in American men, with an estimated 27360 patients dying of castration-resistant prostate cancer (CRPC) in 2009. ${ }^{1}$ Furthermore, in recent years, there has been a more rapid increase in the incidence and mortality rates in Asian countries. ${ }^{2}$ Androgen deprivation therapy, including surgical orchiectomy and luteinizing hormone-releasing hormone agonists are the primary treatments for patients with advanced prostate cancer. These patients respond initially to androgen deprivation therapy within 1-2 years, but eventually they progress to CRPC. Eventually CRPC develops followed by androgen deprivation therapy after 1 to 2 years' response time. ${ }^{3}$ Combination chemotherapy based on docetaxel is the standard treatment for patients with CRPC. ${ }^{4,5}$ However, no standard treatment options are established once patients with CRPC progress. Moreover, docetaxel as an antimicrotubule drug has its limitations, including drug resistance and side effects caused by drug-binding site mutations on $\beta$-tubulin, ${ }^{6}$ overexpression of P-glycoprotein ${ }^{7}$ and $\beta$-tubulin, ${ }^{8}$ and neurotoxicity. ${ }^{9}$ Therefore, there is an urgent need to develop alternative treatment strategies.

Eg5, also known as kinesin spindle protein, ${ }^{10}$ is a member of the kinesin-5 motor proteins, and plays a crucial role in bipolar spindle formation and duplicated chromosome separation during the early phase of mitosis. ${ }^{11,12}$ Inhibition of Eg5 can arrest dividing cells in mitosis followed by cell death, without affecting the function of interphase microtubules, ${ }^{13}$ thus offering an encouraging alternative to microtubule-targeted cancer chemotherapy. The first Eg5-specific inhibitor was identified in 1999 on the basis of phenotype screening, and named monastrol because it can induce monoastral spindle formation. ${ }^{12}$ Inactivation of Eg5 cannot cause peripheral neuropathy because of Eg5 localization to mitotic spindle microtubules but not to interphase microtubules. ${ }^{14}$ Eg5 inhibitors can overcome multidrug resistance to taxanes caused by overexpression of P-glycoprotein because Eg5 cannot be transported out of cells by P-glycoprotein. ${ }^{15,16}$ S-(methoxytrityl)-L-cysteine (S(MeO)TLC),${ }^{17}$ a derivative of $S$-tritylL-cysteine (STLC), ${ }^{18}$ can specifically inhibit Eg5, as does STLC, ${ }^{19}$ and induce monopolar mitotic spindle formation, but it is more than 10 times as potent as STLC. ${ }^{17}$ Meanwhile, the functionalized indoles, such as KPYC10665 (2-(trifluoromethyl)-9H-carbazole), KPYC10666 (2-(tert-butyl)-9H-carbazole) and KPYC10728 (7-(trifluoromethyl)$9 \mathrm{H}$-pyrido[3,4-b]indole), which are synthesized by one-pot $\mathrm{N}$ arylation-oxidative biaryl coupling of anilines and phenyl triflates, ${ }^{20}$ are also potent Eg5 inhibitors. ${ }^{21}$

${ }^{1}$ Department of Urology, Kyoto University, Graduate School of Medicine, Kyoto 606-8507, Japan; ${ }^{2}$ Department of Urology, Provincial Hospital affiliated to Shandong University, Jinan 250021, Shandong, China and ${ }^{3}$ Graduate School of Pharmaceutical Sciences, Kyoto University, Kyoto 606-8507, Japan

Correspondence: Dr O Ogawa (ogawao@kuhp.kyoto-u.ac.jp)

Received: 24 July 2010; Revised: 26 October 2010; Accepted: 1 December 2010; Published online: 7 February 2011 
In our previous study, $\mathrm{S}(\mathrm{MeO}) \mathrm{TLC}$ displayed its potent anticancer efficacy in bladder cancer in vitro and in vivo. ${ }^{22}$ In the present study, we examined Eg5 expression in prostate cancer cells. We also analyzed the relationship between Eg5 expression in clinical samples and clinicopathological characteristics. We assessed the potent anticancer efficacy of $\mathrm{S}(\mathrm{MeO}) \mathrm{TLC}$ both in vitro and in vivo.

\section{MATERIALS AND METHODS}

\section{Cell culture and drug compounds}

The prostate cancer cell lines PC3, DU145 and LNCaP were obtained from the American Type Culture Collection (Rockville, MD, USA). PC $3^{\text {Luc }}$ cell line was also constructed and used. PC3 cells were lipofected with pGL3-control plasmid vector (firefly luciferase gene; Promega, Madison, WI, USA) and pSV2Neo plasmid (a vector for neomycin resistance; American Type Culture Collection), as described previously. ${ }^{23}$ The clone that stably expressed strongest luciferase activity was designated $\mathrm{PC} 3^{\mathrm{Luc}}$. The cells were routinely propagated in RPMI-1640 supplemented with $10 \%$ fetal bovine serum and $1 \%$ penicillin/streptomycin, and incubated at $37{ }^{\circ} \mathrm{C}$ with a humidified $5 \% \mathrm{CO}_{2}$ atmosphere.

Five Eg5 inhibitors were used in our study. KPYC10665, KPYC10666 and KPYC10728 were synthesized in our institute, and STLC and S(MeO)TLC were purchased from Bachem (Bubendorf, Switzerland). All compounds were dissolved in DMSO and stored at $-20{ }^{\circ} \mathrm{C}$.

Eg5 expression in prostate cancer tissue microarrays (TMAs) and cells

After obtaining approval from the Institutional Review Board at Kyoto University Hospital and informed consent, a total of 80 archival specimens of clinically localized prostate cancer patients who underwent radical prostatectomy at our institute were used in the study. TMAs were constructed from these specimens as previously described. ${ }^{24}$ Standard indirect immunoperoxidase assays using primary anti-Eg5 rabbit antibody ( $1: 300$; Cytoskeleton, Denver, CO, USA) were performed to detect Eg5 antigen. Eg5 immunostaining was considered positive if the cytoplasm of $\geqslant 5 \%$ cancer cells showed weak or greater intensity. Ki67 labeling index was determined as previously described. ${ }^{24}$ All pathological evaluations were performed independently by two of the authors (NDX and TK). Assessment of Gleason grading and cancer staging were based on standard hematoxylin and eosin (H\&E) staining and clinical data according to the 2002 American Joint Committee on Cancer TNM classification and the Japanese General Rules for Clinical and Pathological Studies on Prostate cancer (third edition). ${ }^{25,26}$ The correlation between clinicopathological characteristics and Eg5 immunohistological expression was analyzed statistically.

Eg5 expression in prostate cancer cell lines was determined by Western blot analysis using standard methods as described previously. ${ }^{27}$ Briefly, $25 \mu \mathrm{g}$ protein extracts were added to each lane and separated by SDS-polyacrylamide gel electrophoresis $(30 \mathrm{~mA}$ for $120 \mathrm{~min}$ ), then blotted onto a polyvinylidene difluoride membrane (16 V for $120 \mathrm{~min}$ ). After incubated with $5 \%$ non-fat dry milk for an hour at room temperature, membranes were incubated with rabbit primary antibody (1:1000; Cytoskeleton) for Eg5 detection and anti$\beta$-actin mouse antibody (1:20 000; Abcam, Cambridge, UK), which was employed as an internal control. After incubation with corresponding horseradish peroxidase-conjugated secondary antibodies (anti-rabbit, 1:25 000; anti-mouse, 1:10 000), ECL solution (GE Healthcare, Buckinghamshire, UK) was applied to react with the membranes and reactive bands were imaged by a PhosphorImager (GE Healthcare)

\section{Cell viability assay}

Cell viability was determined using the 3-(4,5-dimethylthiazol-2-yl)2,5-diphenyltetrazolium bromide (MTT) assay, as described previously. ${ }^{27}$ Cells were grown in 96 -well plates at a density of $2.5 \times 10^{3}$ cells per well and incubated for $24 \mathrm{~h}$. After that, cells were administered varying concentrations of Eg5 inhibitors, or DMSO alone as a control, for additional $72 \mathrm{~h}$ incubation. The concentrations of $50 \%$ cell growth inhibition $\left(\mathrm{IC}_{50}\right)$ were assessed according to the dose-response curve.

Trypan blue staining was also used to assess the percentage of viable cells, as described previously. ${ }^{27}$

\section{Flow cytometry assay and Hoechst staining}

To assess the cell cycle distribution, DNA content of PC3 cells treated with $\mathrm{S}(\mathrm{MeO}) \mathrm{TLC}$ or vehicle was stained by 7 -amino-actinomycin D (BD Biosciences, San Diego, CA, USA) and assayed by flow cytometry, as described previously. ${ }^{28}$ At least 10000 cells, including floating and attached cells, were collected and analyzed by using a FACSCalibur flow cytometer and CellQuest software (BD Biosciences).

Nuclei of the control and treated cells were stained with $1 \mathrm{mmoll}^{-1}$ Hoechst 33342 solution (Wako, Osaka, Japan). The typical morphological changes of apoptotic cells, such as condensation and fragmentation of the nuclei, were visualized and identified with a fluorescence microscope (Biozero; Keyence, Osaka, Japan).

\section{Immunocytofluorescent staining}

To observe microtubules, $1 \times 10^{5}$ PC3 cells treated with S(MeO)TLC for $16 \mathrm{~h}$ or vehicle alone were fixed and incubated with rabbit anti- $\alpha$ tubulin primary antibody (Cell Signaling Technology, Boston, MA, USA), followed by tetramethylrhodamine-isothiocyanate-conjugated polyclonal swine anti-rabbit IgG (Dako, Glostrup, Denmark). Vectashield Hard Set Mounting Medium with 4,6-diamidino-2-phenylindole (Vector Laboratories, Burlingame, CA, USA) was added for counterstaining of nuclei. Fluorescent microscopic images were acquired using a fluorescence microscope (Biozero), and false color (green) was used for nuclei.

\section{Prostate cancer tumor xenograft studies}

Exponentially growing PC $3^{\mathrm{Luc}}$ cells $\left(5 \times 10^{6}\right.$ cells for one tumor) suspended in $200 \mu \mathrm{l}$ PBS were injected subcutaneously into both flanks of 6-week-old male nude mice (BALB/c AJcI-nu/nu; Japan CLEA, Osaka, Japan). The tumor volume was computed as: volume $=$ length $\times$ width ${ }^{2} \times 0.5236$. When the tumor volume reached $\sim 70 \mathrm{~mm}^{3}, 12$ mice were randomly divided into three groups and treated by daily intraperitoneal injection with 10 or $20 \mathrm{mg} \mathrm{kg}^{-1} \mathrm{~S}(\mathrm{MeO}) \mathrm{TLC}$ or vehicle alone for 5 days. Tumor volume and mouse body weight were monitored every other day. On the day 24 after the first treatment, all mice were killed. Tumors were excised, weighed, formalin fixed and $\mathrm{H} \& \mathrm{E}$ stained for histological analysis. Tumors from two mice in each group that were killed at $24 \mathrm{~h}$ after 5 days treatment with S(MeO)TLC or vehicle alone were also formalin fixed and analyzed histologically using H\&E staining. Mice were kept under specific pathogen-free conditions, and all animal experiments were approved by the Committee on Animal Research at our institute.

\section{Statistical analysis}

SPSS 16.0 software (SPSS Inc., Chicago, IL, USA) was utilized for statistical analysis. Statistical significance was defined as $P<0.05$. 
Two-tailed tests were used. In analysis of TMAs, the differences in age, prostate-specific antigen, Ki-67 labeling index (Ki67 LI) between Eg5positive and -negative groups were analyzed using the Mann-Whitney $U$ test. The correlation of Eg5 expression and Gleason score, pathological T stage, and positive surgical margin was conducted by $\chi^{2}$ test or Fisher exact test. The mean subcutaneous tumor volumes, tumor weights and body weights between groups at the end of observation were compared using one-way ANOVA. The least squares method was used to evaluate the difference between each two groups when ANOVA was significant $(P<0.05)$.

\section{RESULTS}

\section{Expression of Eg5 in prostate cancer}

We evaluated Eg5 expression in prostate cancer cell lines using Western blot analysis. Eg5 expression was identified in all three cell lines, LNCaP, PC3 and DU145 (Figure 1a). We investigated Eg5 expression in prostate cancer clinical samples by immunohistochemistry using TMAs. Eg5 immunostaining was mainly observed in the cytoplasm (Figure 1b). As shown in Table 1, more than half $(55.6 \%$,
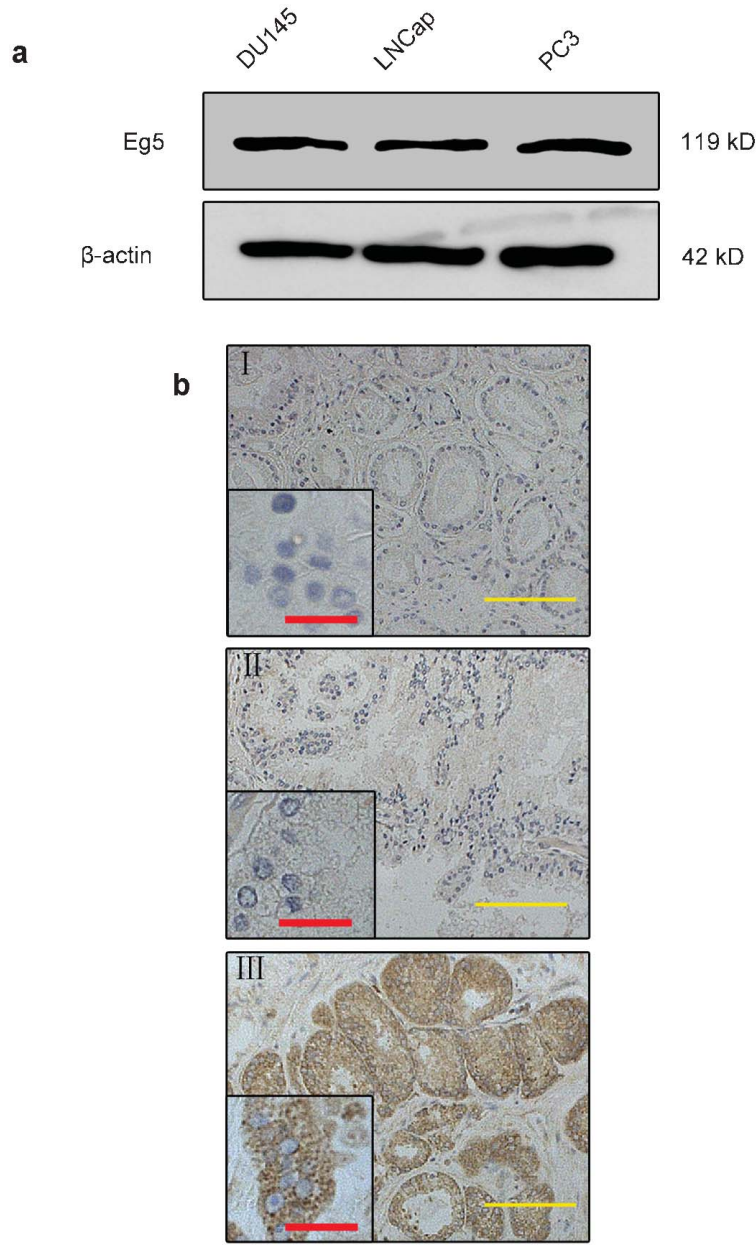

Figure 1 Expression of Eg5 in prostate cancer cells and clinical specimens. (a) Western blot showing Eg5 immunoreactivity in prostate cancer cell lines. (b) Immunohistochemical staining of Eg5 in clinical samples. Eg5 immunostaining was considered positive if $\geqslant 5 \%$ of the cytoplasm of cancer cells showed weak or greater intensity. (I and II) Negative staining of Eg5 in clinical prostate cancer and benign prostate. (III) Representative strong Eg5 immunostaining in clinical prostate cancer. (original magnification, $\times 400$; Scale bars, red $=10 \mu \mathrm{m}$, yellow $=50 \mu \mathrm{m})$.
Table 1 Relationship between Eg5 expression and clinicopathological characteristics $(n=80)$

\begin{tabular}{lcccl}
\hline & \multicolumn{5}{c}{ Eg5 } \\
\cline { 2 - 5 } & $\begin{array}{c}\text { Negative } \\
(\mathrm{n}=36)\end{array}$ & $\begin{array}{c}\text { Positive } \\
(\mathrm{n}=44)\end{array}$ & P value & \multicolumn{1}{c}{ Test } \\
\hline Age (years) & $68(52-76)$ & $69(50-75)$ & 0.81 & Mann-Whitney U test \\
PSA (ng ml $\left.{ }^{-1}\right)$ & $9.9(3.2-41.5)$ & $12.0(4.2-61.3)$ & 0.42 & Mann-Whitney U test \\
GS (\%) & & 30 & - & - \\
$\quad \leqslant 6$ & 25 & 54 & 0.66 & Chi-square test \\
7 & 64 & 16 & - & - \\
$\quad 11$ & 33.3 & 43.2 & 0.41 & Chi-square test \\
PT3- (\%) & 33.3 & 24.3 & 0.47 & Fisher exact test \\
PSM (\%) & $5.0(2.5-24.2)$ & $7.5(2.5-28.3)$ & 0.004 & Mann-Whitney U test \\
Ki67 LI & & & &
\end{tabular}

Abbreviations: GS, Gleason sum; LI, labeling index; PSA, prostate-specific antigen; PSM, positive surgical margin; PT3, pathological T stage.

$44: 80$ ) of prostate cancer clinical specimens exhibited Eg5 expression. Statistical analysis revealed that Eg5 expression was significantly associated with Ki67 LI $(P=0.004)$, although there were no significant relationships between Eg5 expression and the other clinicopathological parameters $(P>0.05)$.

Antiproliferative activity of Eg5 inhibitors against prostate cancer cells

In our study, the antiproliferative activity of five Eg5 inhibitors on prostate cancer cells was assessed using MTT assay. The $\mathrm{IC}_{50}(95 \% \mathrm{CI})$ of the five Eg5 inhibitors on PC3 cells are shown in Table 2 and Figure 2a. All these five Eg5 inhibitors had anticancer effects on PC3 cells. $\mathrm{S}(\mathrm{MeO}) \mathrm{TLC}$ exhibited the most efficient anticancer activity, with an $\mathrm{IC}_{50}$ that was at least 10-fold lower than that of the other agents. Similar results were obtained in DU145 cells (Table 2). S(MeO)TLC also showed a strong inhibitory effect on LNCaP cells (data not shown). Trypan blue staining (Figure $2 \mathrm{~b}$ ) showed that viability of PC3 cells treated with $500 \mathrm{nmol} \mathrm{l}^{-1} \mathrm{~S}(\mathrm{MeO}) \mathrm{TLC}$ for $48 \mathrm{~h}$ decreased significantly in comparison with the controls ( $t$ test, $P<0.01$ ).

MTT assay and trypan blue staining verified that Eg5 inhibitors can substantially inhibit prostate cancer cell proliferation and promote cell death. To explore the mechanism by which $\mathrm{S}(\mathrm{MeO}) \mathrm{TLC}$ exerts its antiproliferative activity in prostate cancer cell lines, the cell cycle distribution analysis was performed by flow cytometry (Figure 3 ). Compared with the control, the $\mathrm{G}_{2} / \mathrm{M}$ phase of PC3 cells after treatment with $500 \mathrm{nmol}^{-1} \mathrm{~S}(\mathrm{MeO}) \mathrm{TLC}$ increased considerably. The percentage of mitotic cells reached a peak after $16 \mathrm{~h}$ of treatment $\left(\mathrm{G}_{2} / \mathrm{M}\right.$ phase cells, $\left.92.1 \pm 4.3 \%\right)$. After mitotic arrest, the proportion of apoptotic cells $\left(\mathrm{subG}_{1}\right)$ increased to $2.3 \pm 0.5 \%$ and $15.5 \pm 2.4 \%$, after 24 and $48 \mathrm{~h}$ of treatment, respectively. Hoechst 33342 staining

Table 2 IC $_{50}$ values of five Eg5 inhibitors in PC 3 and DU145 cells determined by MTT assay

\begin{tabular}{lcc}
\hline \multirow{2}{*}{ Eg5 inhibitors } & \multicolumn{2}{c}{ IC $_{50}\left(95 \%\right.$ confidence interval) $\left(\mu \mathrm{mol} \Gamma^{-1}\right)$} \\
\cline { 2 - 3 } & PC3 & DU145 \\
\hline KPYC10665 & $6.54(6.13-6.98)$ & $12.1(11.2-12.9)$ \\
KPYC10666 & $6.78(6.21-7.37)$ & $14.6(13.4-15.9)$ \\
KPYC10728 & $1.44(1.23-1.67)$ & $2.70(2.33-3.16)$ \\
STLC & $1.10(0.93-1.32)$ & $2.30(1.92-2.75)$ \\
S(MeO)TLC & $0.107(0.081-0.137)$ & $0.408(0.361-0.467)$ \\
\hline
\end{tabular}

Abbreviations: MTT, 3-(4,5-dimethylthiazol-2-yl)-2,5-diphenyltetrazolium bromide; S(MeO)TLC, S-(methoxytrityl)-L-cysteine; STLC, S-trityl-L-cysteine. 

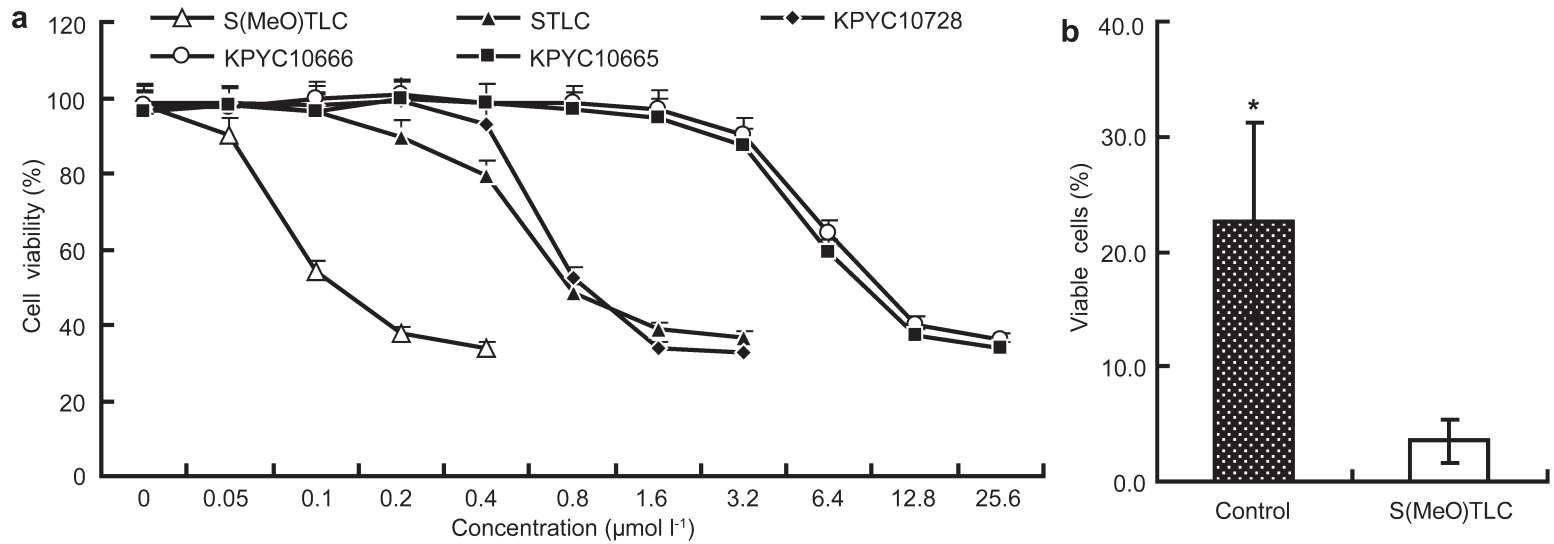

Figure 2 Antiproliferative effects of Eg5 inhibitors on prostate cancer cells. (a) After exposure of PC3 cells to serial dilutions of five Eg5 inhibitors or vehicle control for $72 \mathrm{~h}$, cell viability was analyzed using the MTT assay. Quantification of each value is from triplicate independent experiments. (b) Percentage of viable PC3 cells treated with $500 \mathrm{nmol} \mathrm{I}^{-1} \mathrm{~S}(\mathrm{MeO}) \mathrm{TLC}$ for $48 \mathrm{~h}$ or no treatment were quantified and compared by trypan blue staining; the difference between the two groups was significant $(n=8, * P<0.01)$. MTT, 3-(4,5-dimethylthiazol-2-yl)-2,5-diphenyltetrazolium bromide; S(MeO)TLC, S-(methoxytrityl)-L-cysteine.

revealed that a majority of monopolar spindle cells arrested in mitosis were observed at $16 \mathrm{~h}$ after treatment with $\mathrm{S}(\mathrm{MeO}) \mathrm{TLC}$, and typical nuclear morphological changes of apoptotic cells with condensation and fragmentation of the nuclei were also identified at $48 \mathrm{~h}$ after treatment (Figure 3c). Cells with apoptotic morphology increased significantly after $48 \mathrm{~h}$ of treatment (Figure $3 \mathrm{~d}, P<0.05$ ). The distinctive monopolar spindle morphology with a rosette-like phenotype induced by $\mathrm{S}(\mathrm{MeO}) \mathrm{TLC}$ was further visualized by immunofluorescence assay (Figure 3e), and such cells also increased significantly after $16 \mathrm{~h}$ of treatment (Figure $3 \mathrm{f}, P<0.01$ ). Collectively, these data confirmed that the antiproliferative activity of $\mathrm{S}(\mathrm{MeO}) \mathrm{TLC}$ in prostate cancer cells is induced by mitotic arrest followed by apoptosis.

\section{Efficacy of S(MeO)TLC in the prostate cancer xenograft model} Our previous study showed that S(MeO)TLC $\left(400 \mu \mathrm{g} \mathrm{kg}^{-1}\right.$ to $\left.20 \mathrm{mg} \mathrm{kg}^{-1}\right)$ exhibited significant anticancer efficacy $(P<0.05)$ in the human bladder cancer (KU7) subcutaneous xenograft models in a dose-dependent manner. ${ }^{22}$ Also, there was no significant difference $(P>0.05)$ in tumor growth between the 20 and $30 \mathrm{mg} \mathrm{kg}^{-1}$ groups. Among the five Eg5 inhibitors tested, $\mathrm{S}(\mathrm{MeO}) \mathrm{TLC}$ was the most effective one for the inhibition of KU7 xenograft tumor growth, and the $\mathrm{IC}_{50}$ of $\mathrm{S}(\mathrm{MeO}) \mathrm{TLC}$ on KU7 and PC3 cells was almost the same. Therefore, in our present study, we only evaluated the anticancer efficacy of $\mathrm{S}(\mathrm{MeO}) \mathrm{TLC}$ in $\mathrm{PC}^{\mathrm{Luc}}$ subcutaneous xenograft models using doses of 10 and $20 \mathrm{mg} \mathrm{kg}^{-1}$ and an equal amount of vehicle as a control. As shown in Figure 4a, on day 24 after the first treatment, $\mathrm{S}(\mathrm{MeO}) \mathrm{TLC}$ considerably inhibited subcutaneous tumor growth in a dose-dependent manner $(P<0.05)$. At the end of the observation, we also compared mean final tumor weights between treatment and control groups. The data confirmed that difference in the mean final tumor weights between the two groups was statistically significant (Figure $4 \mathrm{~b}, P<0.05$ ). No obvious body weight changes and other toxic events such as motor disorder and mortality were seen in any group (data not shown). The microscopic appearance of the tumors is shown in Figure 4c. Characteristic monopolar spindle mitotic cells were observed in $\mathrm{H} \& \mathrm{E}$-stained tumors from the $\mathrm{S}(\mathrm{MeO}) \mathrm{TLC}$-treated mice, but not in the control group (Figure 4c).

\section{DISCUSSION}

Cancer cells enter into the cell cycle and undergo uncontrolled mitosis permanently, which results in unlimited tumor growth. Thus, drugs that interfere with mitosis have emerged as the most successful che- motherapeutic agents in clinical use today. ${ }^{29,30}$ Among them, antimicrotubule agents, including taxanes and vinca alkaloids that disturb microtubule dynamics of mitosis, represent the most effective anticancer drugs. ${ }^{29,30}$ Given the success of taxanes in cancer therapy by perturbing mitosis, Eg5, which is more highly expressed in proliferating tissues during mitosis, ${ }^{31}$ is considered as an attractive target for cancer chemotherapy.

Accumulating evidence also indicates that Eg5 inhibition is especially relevant in the treatment of CRPC. In addition to sharing the target molecules with taxanes, Eg5 inhibitors can also exhibit powerful anticancer activity in taxol-resistant cancer cells, and they can overcome taxane resistance. ${ }^{16}$ In addition, they can overcome taxanerelated peripheral neurotoxicity. ${ }^{13,32}$ It has been also reported that, in androgen-independent progression of prostate cancer cells, the androgen receptor distinctly upregulates M-phase cell-cycle genes to promote androgen-independent cell proliferation. ${ }^{33}$ These observations provide us with a strong rationale to utilize Eg5 inhibitors in the treatment of CRPC.

In the present study, we found a correlation between $\mathrm{Eg} 5$ immunohistological expression and clinicopathological characteristics, using TMAs of prostate cancer clinical specimens. Although Eg5 expression was not significantly $(P>0.05)$ associated with age, initial prostatespecific antigen, pathological T stage, positive surgical margin status, nor Gleason score, we did observe a significant correlation $(P=0.004)$ between Eg5 expression and Ki67 LI (the proliferation marker), which is consistent with preferential expression of Eg5 in proliferating tissues. ${ }^{31}$ Furthermore, more than half the prostate cancer specimens showed Eg5 expression. Meanwhile, western blotting analysis showed that Eg5 expression was also present in all three prostate cancer cell lines, LNCaP, PC3 and DU145. To summarize, Eg5 could be a potential molecular target in prostate cancer chemotherapy.

To the best of our knowledge, there have been two systematic studies involving Eg5 inhibition in prostate cancer. ${ }^{34,35}$ These have revealed that docetaxel-resistant and non-resistant prostate cancer cell lines showed almost the same sensitivity to antisense oligonucleotide or STLC treatment. ${ }^{34}$ In contrast to the antisense oligonucleotide and STLC used in those two studies, in our previous study, our target Eg5 inhibitor, $\mathrm{S}(\mathrm{MeO}) \mathrm{TLC}\left(20 \mu \mathrm{moll}^{-1}\right)$, was at least 10 -fold more potent for inhibition of cell proliferation, and was extremely specific to Eg5, without affecting other structurally and functionally related mitotic kinesins. ${ }^{17}$ Furthermore, our current study confirmed that 


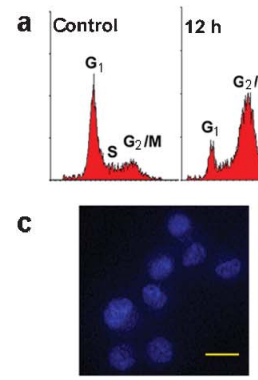

Control

e

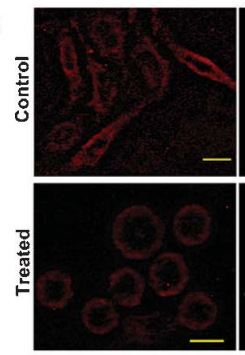

a-tubulin

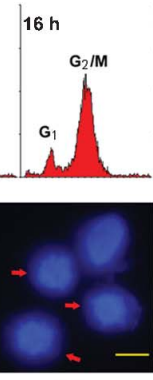

$16 \mathrm{~h}$
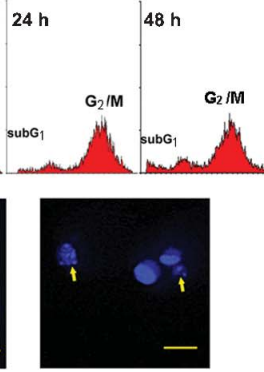

$48 \mathrm{~h}$
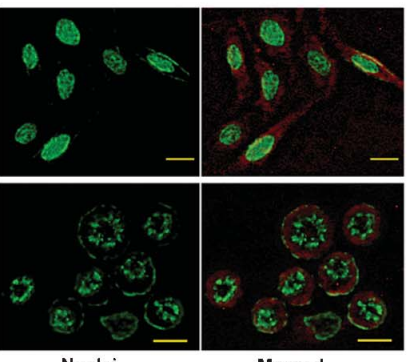

Nuclei

Merged
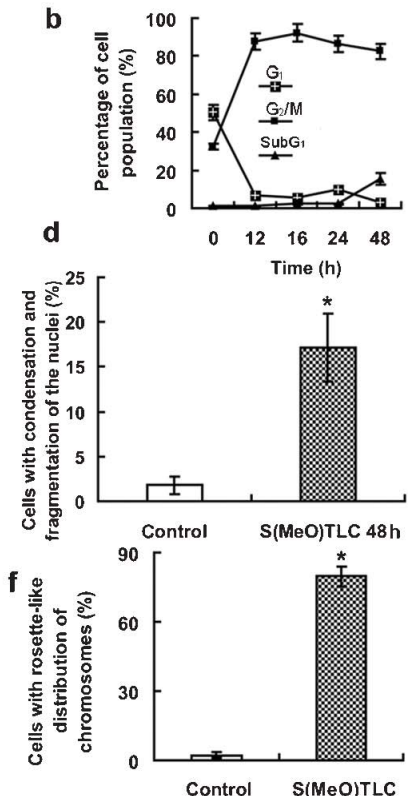

Figure 3 S(MeO)TLC induces prostate cancer cells arrested at mitosis, followed by apoptosis. (a) After exposure of PC3 cells to 500 nmol I-1 S(MeO)TLC, flow cytometry was performed to determine cell cycle distribution. (b) Graphical representation of time-dependent changes in the percentage of $\mathrm{G}_{1}$, $\mathrm{G}_{2} / \mathrm{M}$ and subG $\mathrm{G}_{1}$ cell populations. (c) After exposure of PC3 cells to $500 \mathrm{nmol}^{-1} \mathrm{~S}(\mathrm{MeO}) \mathrm{TLC}$ or vehicle, nuclei were stained with Hoechst 33342 and visualized by fluorescent microscopy. Monopolar spindle phenotype (red arrow) and the typical morphological hallmarks of apoptosis (yellow arrow) were observed in S(MeO)TLC-treated cells. (d) A significant difference in the percentage of cells exhibiting apoptotic morphology, as in (c), was observed between the control and treated groups ( $t$ test, $n=5$, $* P<0.05)$. (e) After exposure of PC3 cells to $500 \mathrm{nmol}{ }^{-1} \mathrm{~S}(\mathrm{MeO}) \mathrm{TLC}$ or vehicle for $16 \mathrm{~h}$, cells were stained using DAPI and antitubulin antibody. The typical monoastral-mitotic phenotype with a rosette-like distribution of chromosomes was observed in S(MeO)TLC-treated cells. (f) Significant difference in the proportion of cells with rosette-like distribution of chromosomes, as in (e), was observed between the groups $(t$ test, $n=5$, * $P<0.01$ ). (Bars $=20 \mu \mathrm{m}$ in (c and $\mathbf{e})$ ). DAPI, 4,6diamidino-2-phenylindole; S(MeO)TLC, S-(methoxytrityl)-L-cysteine.
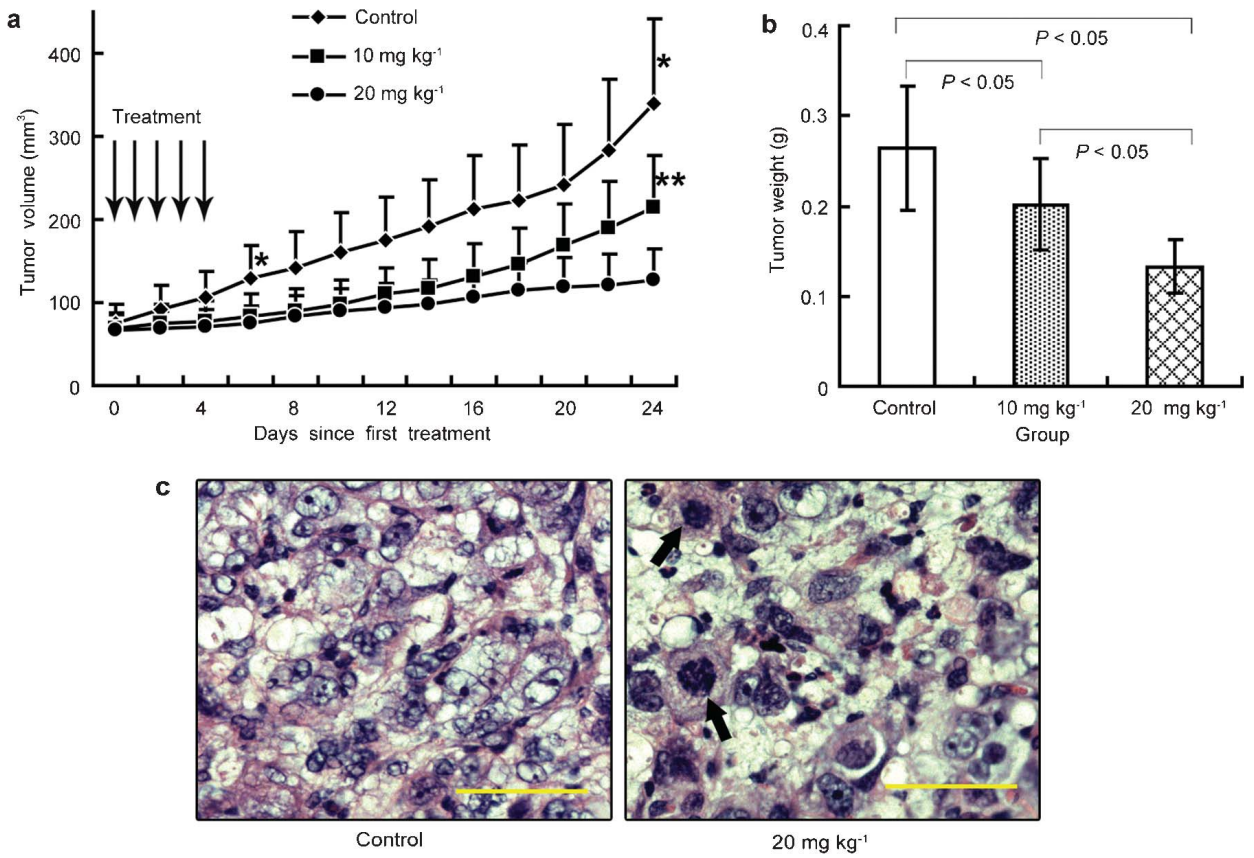

Figure 4 Anticancer efficacy of S(MeO)TLC in subcutaneous xenograft tumor models. (a) After successful establishment of subcutaneous tumors, 10 or 20 mg kg ${ }^{-1}$ $\mathrm{S}(\mathrm{MeO}) \mathrm{TLC}$ or an equal volume of vehicle were administered intraperitoneally daily for 5 days (arrows). Tumor volumes were measured every other day and shown as mean \pm s.d. $\left(\mathrm{mm}^{3}\right)$. Each group consisted of eight tumors. From day 6 after the first treatment, significant differences were observed between the S(MeO)TLC and control groups ( $t$ test, $* P<0.05$ ). Significant differences were observed between the 10 and $20 \mathrm{mg} \mathrm{kg}^{-1} \mathrm{~S}(\mathrm{MeO}) \mathrm{TLC}$ groups $(t$ test, $* * P<0.05)$. (b) The mean final tumor weights were assessed, and S(MeO)TLC exhibited its anticancer efficacy in a dose-dependent manner $(P<0.05)$. (c) The distinctive monopolar spindle mitotic cells (arrows) were observed in H\&E-stained tumors after five consecutive days of treatment in the $20 \mathrm{mg} \mathrm{kg}^{-1}$ group, but not in the control group (original magnification, $\times 200$; bars $=50 \mu \mathrm{m}$ ). H\&E, hematoxylin and eosin; S(MeO)TLC, S-(methoxytrityl)-L-cysteine 
$\mathrm{S}(\mathrm{MeO}) \mathrm{TLC}$ exhibited more efficient antiproliferative activity compared with STLC and the other three newly synthesized agents. ${ }^{19}$ Thereafter, the mechanism of cell growth inhibition in prostate cancer cell lines caused by $\mathrm{S}(\mathrm{MeO}) \mathrm{TLC}$ treatment was clarified. S(MeO)TLC exerted its antiproliferative effect by arresting cell-cycle progression at the $\mathrm{G}_{2} / \mathrm{M}$ phase, with a distinctive monopolar spindle phenotype and a rosette-like chromosomal arrangement. Besides, the discovery of such a distinctive monopolar spindle phenotype validates the specificity of $\mathrm{S}(\mathrm{MeO}) \mathrm{TLC}$ for Eg5 inhibition and the indispensable role of Eg5 in bipolar spindle formation. Thus, cancer cell death induced by $\mathrm{S}(\mathrm{MeO}) \mathrm{TLC}$ treatment was provoked principally by prolonged mitotic arrest in a time-dependent manner.

In view of the potent anticancer efficacy of $\mathrm{S}(\mathrm{MeO}) \mathrm{TLC}$ in vitro, its inhibitory effect in subcutaneous xenograft tumor models was further assessed. As expected, $\mathrm{S}(\mathrm{MeO}) \mathrm{TLC}$ displayed its significant dosedependent antitumor efficacy in vivo $(P<0.05)$. In addition, the histological observation of characteristic mitotic cells with monopolar spindle phenotype suggested that $\mathrm{S}(\mathrm{MeO}) \mathrm{TLC}$ treatment resulted in an antitumor effect through induction of mitotic arrest.

In summary, Eg5 could be a good target for prostate cancer chemotherapy. We demonstrated that $\mathrm{S}(\mathrm{MeO}) \mathrm{TLC}$, as a novel Eg5 inhibitor, exhibited significant anticancer efficacy $(P<0.05)$ in prostate cancer both in vitro and in vivo. In consideration of the robust preclinical anticancer attributes of $\mathrm{S}(\mathrm{MeO}) \mathrm{TLC}$, we believe that $\mathrm{S}(\mathrm{MeO}) \mathrm{TLC}$ might exhibit promising clinical efficacy in prostate cancer. Further evaluations of the safety of $\mathrm{S}(\mathrm{MeO}) \mathrm{TLC}$ in prostate cancer patients and combination chemotherapy should be made before its clinical application.

\section{AUTHOR CONTRIBUTIONS}

NDX, STD, RS, KN and TK carried out the study, analyzed the data and wrote the manuscript. SO and NF were involved in the design and preparation of Eg5 inhibitors. TI, JL, $\mathrm{HN}$ and $\mathrm{OO}$ were involved in the study design, data management and analysis of the study.

\section{COMPETING FINANCIAL INTERESTS}

The authors declare no competing financial interests.

\section{ACKNOWLEDGMENTS}

This research was supported by the Targeted Proteins Research Program and Grants-in-Aid for Scientific Research from Ministry of Education, Culture, Sports, Science and Technology (MEXT), Japan.

1 Jemal A, Siegel R, Ward E, Hao Y, Xu J et al. Cancer statistics, 2009. CA Cancer J Clin 2009; 59: 225-49.

2 Sim HG, Cheng CW. Changing demography of prostate cancer in Asia. Eur J Cance 2005; 41: 834-45.

3 Sternberg CN. Systemic chemotherapy and new experimental approaches in the treatment of metastatic prostate cancer. Ann Oncol 2008; 19 Suppl 7: vii91-5.

4 Petrylak DP, Tangen CM, Hussain MH, Lara PN Jr, Jones JA et al. Docetaxel and estramustine compared with mitoxantrone and prednisone for advanced refractory prostate cancer. N Engl J Med 2004; 351: 1513-20.

5 Tannock IF, de Wit R, Berry WR, Horti J, Pluzanska A et al. Docetaxel plus prednisone or mitoxantrone plus prednisone for advanced prostate cancer. N Engl J Med 2004; 351: 1502-12.

6 Giannakakou P, Gussio R, Nogales E, Downing KH, Zaharevitz D et al. A common pharmacophore for epothilone and taxanes: molecular basis for drug resistance conferred by tubulin mutations in human cancer cells. Proc Natl Acad Sci USA 2000; 97: 2904-9.

7 Geney R, Ungureanu M, Li D, Ojima I. Overcoming multidrug resistance in taxane chemotherapy. Clin Chem Lab Med 2002; 40: 918-25.
8 Mozzetti S, Ferlini C, Concolino P, Filippetti F, Raspaglio G et al. Class III beta-tubulin overexpression is a prominent mechanism of paclitaxel resistance in ovarian cancer patients. Clin Cancer Res 2005; 11: 298-305.

9 Pronk LC, Hilkens PH, van den Bent MJ, van Putten WL, Stoter G et al. Corticosteroid co-medication does not reduce the incidence and severity of neurotoxicity induced by docetaxel. Anticancer Drugs 1998; 9: 759-64.

10 Sawin KE, LeGuellec K, Philippe M, Mitchison TJ. Mitotic spindle organization by a plus-end-directed microtubule motor. Nature 1992; 359: 540-3.

11 Blangy A, Lane HA, d'Herin P, Harper M, Kress M et al. Phosphorylation by p34cdc2 regulates spindle association of human Eg5, a kinesin-related motor essential for bipolar spindle formation in vivo. Cell 1995; 83: 1159-69.

12 Mayer TU, Kapoor TM, Haggarty SJ, King RW, Schreiber SL et al. Small molecule inhibitor of mitotic spindle bipolarity identified in a phenotype-based screen. Science 1999; 286: 971-4.

13 Sakowicz R, Finer JT, Beraud C, Crompton A, Lewis E et al. Antitumor activity of a kinesin inhibitor. Cancer Res 2004; 64: 3276-80.

14 Sawin KE, Mitchison TJ. Mutations in the kinesin-like protein Eg5 disrupting localization to the mitotic spindle. Proc Natl Acad Sci USA 1995; 92: 4289-93.

15 Peters T, Lindenmaier H, Haefeli WE, Weiss J. Interaction of the mitotic kinesin Eg5 inhibitor monastrol with P-glycoprotein. Naunyn Schmiedebergs Arch Pharmacol 2006; 372: 291-9.

16 Marcus Al, Peters U, Thomas SL, Garrett S, Zelnak A et al. Mitotic kinesin inhibitors induce mitotic arrest and cell death in Taxol-resistant and -sensitive cancer cells. $J$ Biol Chem 2005; 280: 11569-77.

17 Ogo N, Oishi S, Matsuno K, Sawada J, Fujii N et al. Synthesis and biological evaluation of L-cysteine derivatives as mitotic kinesin Eg5 inhibitors. Bioorg Med Chem Lett 2007; 17: 3921-4.

18 Kozielski F, Skoufias DA, Indorato RL, Saoudi Y, Jungblut PR et al. Proteome analysis of apoptosis signaling by $S$-trityl-L-cysteine, a potent reversible inhibitor of human mitotic kinesin Eg5. Proteomics 2008; 8: 289-300.

19 Debonis S, Skoufias DA, Indorato RL, Liger F, Marquet B et al. Structure-activity relationship of $S$-trityl-L-cysteine analogues as inhibitors of the human mitotic kinesin Eg5. J Med Chem 2008; 51: 1115-25.

20 Watanabe T, Oishi S, Fujii N, Ohno H. Palladium-catalyzed direct synthesis of carbazoles via one-pot $\mathrm{N}$-arylation and oxidative biaryl coupling: synthesis and mechanistic study. J Org Chem 2009; 74: 4720-6.

21 Oishi S, Watanabe T, Sawada J, Asai A, Ohno H et al. Kinesin spindle protein (KSP) inhibitors with 2,3-fused indole scaffolds. J Med Chem 2010; 53: 5054-8.

22 Ding S, Nishizawa K, Kobayashi T, Oishi S, Lv J et al. A potent chemotherapeutic strategy for bladder cancer: (S)-methoxy-trityl-L-cystein, a novel Eg5 inhibitor. J Urol 2010; 184: 1175-81.

23 Nogawa M, Yuasa T, Kimura S, Kuroda J, Sato K et al. Monitoring luciferase-labeled cancer cell growth and metastasis in different in vivo models. Cancer Lett 2005; 217 243-53.

24 Inoue T, Segawa T, Shiraishi T, Yoshida T, Toda Y et al. Androgen receptor, Ki67, and p53 expression in radical prostatectomy specimens predict treatment failure in Japanese population. Urology 2005; 66: 332-7.

25 Prostate. In: Greene F, Page D, Fleming I, editors. American Joint Committee on Cancer Staging Manual. 6th ed. New York: Springer; 2002. pp309-16.

26 General Rules for Clinical and Pathological Studies on Prostate Cancer. 3rd ed. Tokyo: Japanese Urological Association, Japanese Society of Pathology; 2001.

27 Matsui Y, Watanabe J, Ding S, Nishizawa K, Kajita Y et al. Dicoumarol enhances doxorubicin-induced cytotoxicity in p53 wild-type urothelial cancer cells through p38 activation. BJU Int 2010; 105: 558-64.

28 Inoue T, Yoshida T, Shimizu Y, Kobayashi T, Yamasaki T et al. Requirement of androgen-dependent activation of protein kinase Czeta for androgen-dependent cell proliferation in LNCaP Cells and its roles in transition to androgen-independent cells. Mol Endocrinol 2006; 20: 3053-69.

29 Schmidt M, Bastians H. Mitotic drug targets and the development of novel anti-mitotic anticancer drugs. Drug Resist Updat 2007; 10: 162-81.

30 Jackson JR, Patrick DR, Dar MM, Huang PS. Targeted anti-mitotic therapies: can we improve on tubulin agents? Nat Rev Cancer 2007; 7: 107-17.

31 Hegde PS, Cogswell J, Carrick K, Jackson J, Wood KW et al. Differential gene expression analysis of kinesin spindle protein in human solid tumors. Proc Am Soc Clin Oncol 2003; 22: 535.

32 Nakai R, lida S, Takahashi T, Tsujita T, Okamoto S et al. K858, a novel inhibitor of mitotic kinesin Eg5 and antitumor agent, induces cell death in cancer cells. Cancer Res 2009; 69: 3901-9.

33 Wang Q, Li W, Zhang Y, Yuan X, Xu K et al. Androgen receptor regulates a distinct transcription program in androgen-independent prostate cancer. Cell 2009; 138: 245-56.

34 Wiltshire C, Singh BL, Stockley J, Fleming J, Doyle B et al. Docetaxel-resistant prostate cancer cells remain sensitive to $S$-trityl-L-cysteine-mediated Eg5 inhibition. Mol Cancer Ther 2010; 9: 1730-9.

35 Hayashi N, Koller E, Fazli L, Gleave ME. Effects of Eg5 knockdown on human prostate cancer xenograft growth and chemosensitivity. Prostate 2008; 68: 1283-95. 